
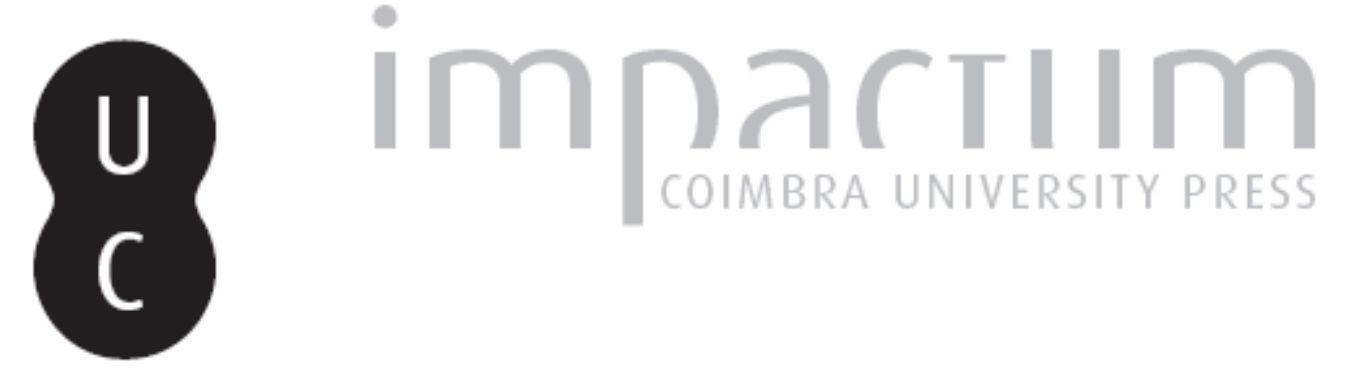

\title{
Redes sociais: perceções de aprendizagem em ambiente formal, nãoformal e informal por parte de jovens, seus encarregados de educação e seus professores
}

Autor(es): $\quad$ Tomé, Vitor

Publicado por: Imprensa da Universidade de Coimbra

URL persistente:

URI:http://hdl.handle.net/10316.2/38141

DOI:

DOI:http://dx.doi.org/10.14195/2183-5462_27_4

Accessed : $\quad$ 26-Apr-2023 10:27:17

A navegação consulta e descarregamento dos títulos inseridos nas Bibliotecas Digitais UC Digitalis, UC Pombalina e UC Impactum, pressupõem a aceitação plena e sem reservas dos Termos e Condições de Uso destas Bibliotecas Digitais, disponíveis em https://digitalis.uc.pt/pt-pt/termos.

Conforme exposto nos referidos Termos e Condições de Uso, o descarregamento de títulos de acesso restrito requer uma licença válida de autorização devendo o utilizador aceder ao(s) documento(s) a partir de um endereço de IP da instituição detentora da supramencionada licença.

Ao utilizador é apenas permitido o descarregamento para uso pessoal, pelo que o emprego do(s) título(s) descarregado(s) para outro fim, designadamente comercial, carece de autorização do respetivo autor ou editor da obra.

Na medida em que todas as obras da UC Digitalis se encontram protegidas pelo Código do Direito de Autor e Direitos Conexos e demais legislação aplicável, toda a cópia, parcial ou total, deste documento, nos casos em que é legalmente admitida, deverá conter ou fazer-se acompanhar por este aviso.

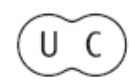




\section{Mediag Ornalismo}

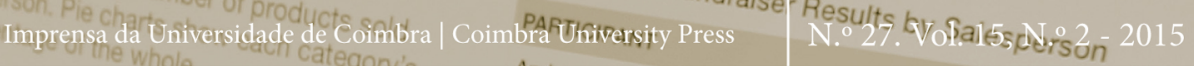

\section{U.m

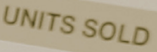 \\ EDUCÂÇÃO PARA OS}

MEDIA NA ERA DIGITAL
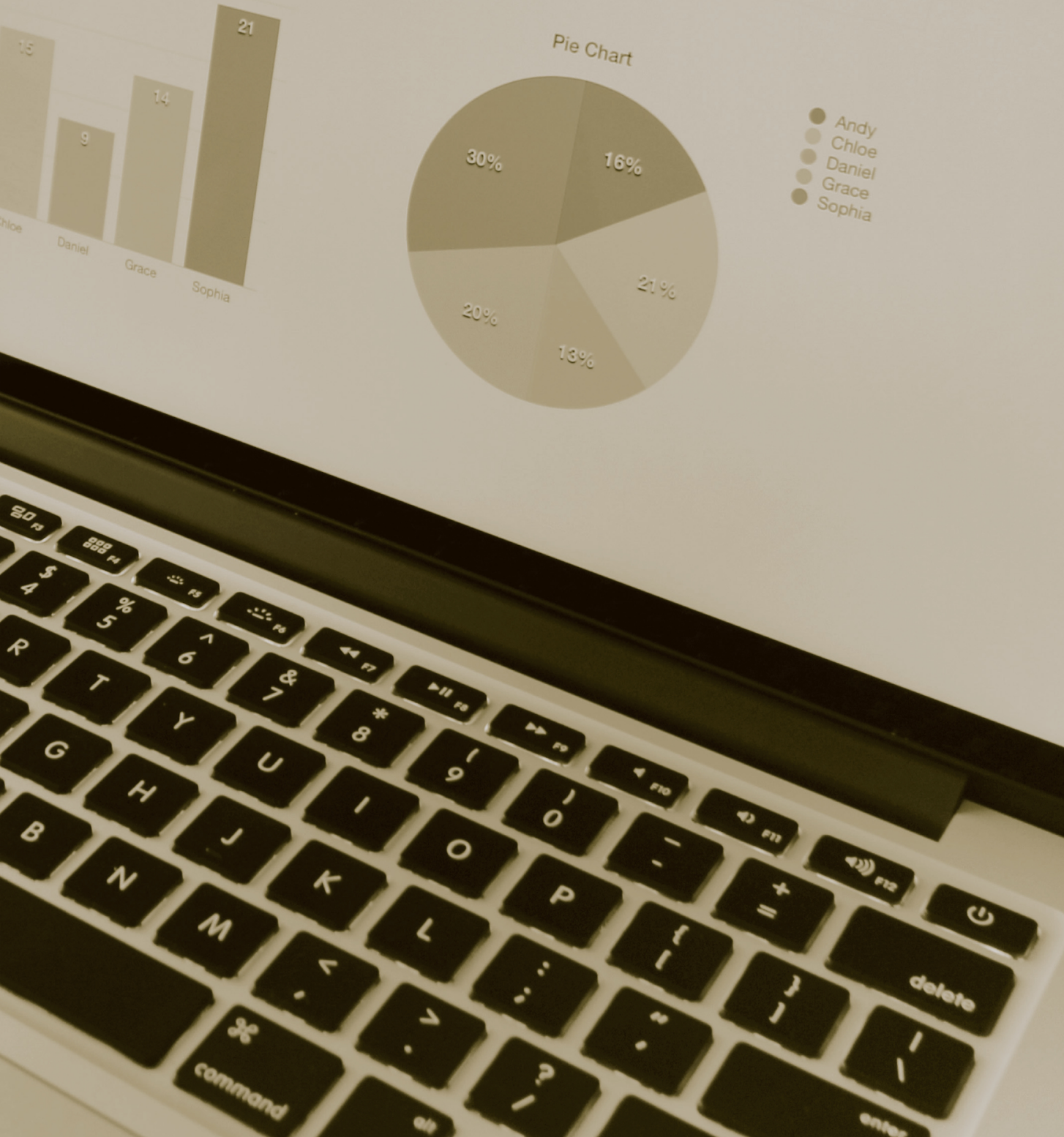


\author{
REDES SOCIAIS: PERCEÇÕES DE APRENDIZAGEM \\ EM AMBIENTE FORMAL, NÃO-FORMAL E INFORMAL \\ POR PARTE DE JOVENS, SEUS ENCARREGADOS \\ DE EDUCAÇÃO E SEUS PROFESSORES \\ ONLINE SOCIAL NETWORKS: PERCEPTIONS OF LEARNING \\ IN FORMAL, NON-FORMAL AND INFORMAL CONTEXTS BY \\ YOUNGSTERS, THEIR TEACHERS AND ADMINISTRATORS
}

\author{
VITOR TOMÉ \\ VITOR@RVJ.PT \\ CIAC - UNIVERSIDADE DO ALGARVE
}

Resumo

As redes sociais online (RSO) são ferramentas com potencial no desenvolvimento da literacia digital, focada na aquisição de competências técnicas, de análise crítica e de práticas de formação, contextualmente situada em contextos de aprendizagem formal e informal complementares. Apresentamos neste artigo os resultados de uma investigação que visou compreender se há condições para concretizar o potencial das RSO, pelo que inquirimos jovens portugueses (10-16), seus professores e encarregados de educação (EE), a que se seguiram entrevistas de grupos focais e entrevistas semiestruturadas, seguindo o design dos métodos mistos. Os professores reconhecem potencial pedagógico às RSO, mas consideram, tal como os alunos e os $\mathrm{EE}$, que a aprendizagem com recurso às RSO ocorre sobretudo no contexto informal, que veem como quase estanque em relação ao formal, não se sentindo preparados para os integrar no caso específico das RSO.

\title{
Palavras-chave
}

Redes sociais online, aprendizagem formal, não-formal e informal, jovens, encarregados de educação, professores de $2 .^{\circ}$ e $3 .{ }^{\circ}$ Ciclos.

\section{Abstract}

Online social networks (OSN) provide potential opportunities to develop digital literacy, which includes the acquisition of technical skills, critical analysis and contextually situated learning practices in complimentary formal and informal contexts. In this article, we present the results of a study about the conditions to fulfill the potential of RSO. We inquired young Portuguese children (ages 10 to 16 years-old), their teachers and administrators, through focus groups and semi-structured interviews, according to the mixed methods research design. Our results indicate that teachers recognize a pedagogical potential to OSN, but consider, as students and administrators do, that learning using the OSN occurs mainly informally outside of the educational setting. Teachers also stated that they don't feel prepared to integrate these tools into the context of their educational curriculum.

\section{KEYWORDS}

Online social networks, digital literacy, young people, administrators, compulsory education teachers. 


\title{
REDES SOCIAIS: PERCEÇÕES DE APRENDIZAGEM \\ EM AMBIENTE FORMAL, NÃO-FORMAL E INFORMAL \\ POR PARTE DE JOVENS, SEUS ENCARREGADOS \\ DE EDUCAÇÃO E SEUS PROFESSORES
}

\author{
VITOR TOMÉ \\ VITOR@RVJ.PT \\ CIAC - UNIVERSIDADE DO ALGARVE
}

\section{Introdução}

A Internet e os media sociais estão hoje presentes na vida quotidiana de crianças e jovens europeus (9-16 anos), sendo que a "maioria [cerca de 60\%] acede todos os dias ou quase todos os dias" e cada vez mais a partir de dispositivos móveis (Ólafsson et al., 2014, p. 24). Um estudo europeu concluiu que 0 acesso diário ocorre mais em casa e no quarto de dormir (55\%) do que fora de casa (17\%). E se os que usam a Internet diariamente recorrem mais a computadores portáteis $(46 \%), 0$ smartphone é usado por $41 \%$, mais que o computador fixo (33\%) e o tablet $(23 \%)$ (Mascheroni \& Cuman, 2014, p. 6).

Nos Estados Unidos da América, 92\% dos jovens (13-17 anos) acedem à Internet diariamente, sendo que $24 \%$ estão ligados 'quase constantemente', $56 \%$ acedem várias vezes por dia, só $12 \%$ afirmam aceder uma vez por dia. Frequências de uso semanais (6\%) ou superiores (2\%) são marginais. Os jovens que usam dispositivos móveis têm frequências de acesso mais elevadas, sendo que $91 \%$ acedem à Internet a partir desses dispositivos, pelo menos ocasionalmente (Pew Research Center, 2015).

Um estudo português realizado junto de 1814 jovens do ensino básico (14,3\%), secundário (43,8\%) e profissional (41,9\%), com média etária de 16 anos, sendo 90\% menores de 18 anos, revela que 90\% dos indivíduos acedem à Internet todos os dias. Entre os que acedem à Internet, $92 \%$ usam o computador portátil. Segue-se o telemóvel (80\%) e o tablet (38\%), mais referido por alunos do básico (Lopes, 2015).

As atividades mais comuns dos jovens europeus na Internet estão relacionadas com trabalhos escolares (85\%), jogos (83\%), ver vídeos $(76 \%)$, mensagens instantâneas (62\%), publicação de imagens (39\%) e mensagens (31\%), uso da webcam (31\%), o uso de sítios de partilha de ficheiros (16\%) e de blogues (11\%) (Ólafsson et al., 2014, p. 25).

Em Portugal, crianças e jovens dos 9-16 anos usam sobretudo a Internet para trabalhos escolares (89\%), jogos (83\%), ver vídeos (70\%), enviar mensagens instantâneas (69\%) postar mensagens em sítios Internet (11\%), usar sítios de partilha de ficheiros (7\%) e blogues (7\%) (Haddon \& Livingstone, 2012, p. 51).

Os jovens são maioritariamente utilizadores diários de Internet, a que acedem sobretudo ainda através de computador portátil, mas o telemóvel tende a ser o principal meio de acesso. A utilização da Internet é justificada pelos jovens com objetivos escolares, seguidas de objetivos de entretenimento (e.g., jogos, ver vídeos) 
e de comunicação (e.g., publicação e troca de mensagens). Constata-se assim que os jovens adaptaram rapidamente as ferramentas digitais aos seus interesses, designadamente em termos de entretenimento e de utilização das redes sociais (Underwood et al., 2013, p. 479).

Rede social online (RSO) é um grupo de pessoas conectadas na Internet que partilham interesses e atividades comuns, podendo publicar perfis e informação acerca de si próprias (UNESCO, 2011). A que tem atualmente mais utilizadores é o Facebook, que conta com cerca de 1415 milhões de aderentes em todo o mundo (Statista, 2015).

Nos Estados Unidos 89\% dos jovens usam pelo menos uma RSO, sendo o Facebook a mais usada (71\%) (Pew Research, 2015), enquanto na Europa são 68\%, com o Facebook a liderar (Mascheroni \& Cuman, 2014). Em Portugal, 64,3\% dos jovens usam as RSO numa frequência diária, sendo o Facebook a rede preferida por 85,6\% dos utilizadores (Lopes, 2015). Os estudos apontam ainda para uma diversificação no uso de RSO, pois a maioria dos jovens tem um perfil em duas ou mais.

As RSO estão a mudar a natureza dos grupos, das formações sociais e do poder. Alteraram a forma de atribuição de significados a conteúdos dos media, pelo que transformam a sociedade e, em particular, a cultura popular (Gee, 2010). Os utilizadores têm cada vez menos barreiras à expressão artística, beneficiam de um forte apoio à criação e partilha de criações com terceiros, acedem rapidamente a informações de profissionais e amadores, sentem que as suas contribuições têm valor para os outros e sentem algum grau de conexão social com os outros utilizadores (Jenkins, 2009).

0 uso das RSO muda as práticas culturais, que assumem sobretudo um carácter exploratório, pelo que os jovens, em particular, "aprendem através das suas práticas nas redes sociais" (Endrizzi, 2012, p. 12). Quando se interessam por um tema, encontram outros que partilham esses centros de interesse e procuram saber cada vez mais, para serem reconhecidos pelos pares, e evoluem por tentativa-erro.

Os jovens melhoram progressivamente a sua capacidade de utilização de media sociais e mostram uma clara "preferência por uma aprendizagem interativa fora da escola" (Underwood et al., 2013, pp. 479-80), colocando em causa o monopólio da escola formal tradicional e conferindo maior relevância à aprendizagem não-formal e informal.

A aprendizagem formal tem lugar em instituições de educação e formação (Perulli, 2009), é organizada em função de um programa, estruturada, intencional e visa a obtenção de uma certificação (Smith \& Clayton, 2009). É um sistema fechado que funciona de acordo com uma lógica prescrita, assente num currículo e em papéis pré-estabelecidos dos seus agentes, pois os professores ensinam e os alunos aprendem, reproduzindo as aprendizagens em testes para obterem graus (Underwood et al., 2013).

A aprendizagem não-formal é desenvolvida em instituições de educação e formação mas também no local de trabalho, organizações culturais e desportivas e outras associações (Perulli, 2009). Organizada em função de um programa e estruturada, não visa a obtenção de certificação mas sim o desenvolvimento de competências específicas (Smith \& Clayton, 2009). 
A aprendizagem informal decorre da vida quotidiana e pode não ser reconhecida pelos sujeitos aprendentes, por ser não-intencional, carecer de estrutura e de uma associação à instituição escolar (Smith \& Clayton, 2009). É "um sistema de negociação aberto, recetivo a nova informação, ferramentas, tarefas e a novos participantes no decurso de uma atividade" (Underwood et al., 2013, p. 482).

Aprendizagem formal distingue-se de aprendizagem informal a seis níveis (Jenkins, 2009):

a. a formal é conservadora, associada à cultura mais elitista, enquanto a informal é mais vezes experimental e está associada à cultura popular;

b. a formal é mais estática, perdurando no tempo, enquanto a segunda é mais inovadora e não tem uma dimensão temporal previamente definida;

c. a formal tem uma estrutura institucional, enquanto a segunda é mais ou menos organizada, em função dos agentes envolvidos;

d. na formal a comunidade muda pouco ao longo do tempo, enquanto na informal essa comunidade é dinâmica e pode apenas existir no curto prazo;

e. a formal é burocrática e, normalmente, de âmbito nacional, enquanto na informal a comunidade é formada ad-hoc e de localização volátil;

f. na formal, a mobilidade (ex: abandono) está limitada, enquanto na informal os participantes podem abandonar a comunidade de aprendizagem a qualquer momento se, por exemplo, não corresponde às suas expectativas.

Apesar das diferenças, importa perceber se aprendizagem formal e informal podem articular-se na formação integral dos cidadãos. 0 debate está ativo na Europa desde os anos 90 do século XX, pois o reconhecimento de competências não certificadas pela escola é decisivo em termos laborais e sociais, mas "há ainda um longo caminho a percorrer entre a teoria e a prática no que diz respeito à associação entre estes tipos de aprendizagem" (Perulli, 2009, p. 98) e das implicações a ela associadas.

\subsection{Conceito alargado de Literacia e competênCias de literacia digital}

A articulação das aprendizagens formal e informal pressupõe 0 alargamento do conceito de literacia, que mantém a lógica tradicional, assente em ler, escrever, ouvir e falar, mas integra a literacia digital, que consiste em "criar, trabalhar, partilhar, socializar, investigar, jogar, colaborar, comunicar e aprender" (Meyers et al., 2013, p. 356). É que a literacia não é um fenómeno apenas mental mas também sociocultural, estando relacionada com a participação em grupos sociais e culturais, de que resultam experiências mediadas por tecnologias, sejam elas impressas, digitais ou outras (Gee, 2010). Os processos de aprendizagem "não são apenas interiorizados individualmente mas são socialmente distribuídos, com implicações na pedagogia e na instrução" (Underwood et al., 2013, p. 479). É preciso questionar e refletir sobre a natureza da educação, de forma a explorar novos tipos de experiências de aprendizagem para estudantes e professores (idem, p. 481).

Os cidadãos do século XXI precisam de desenvolver três níveis de competências essenciais: 1) as técnicas, para lidarem com as tecnologias digitais (e.g.: acesso, difusão de mensagens); ii) as reflexivas e criativas, para concretizarem a análise 
crítica e produção de mensagens media (Buckingham, 2009; UNESCO, 2011); iii) as sociais ou gerais, decisivas para uma participação efetiva em práticas contextualmente situadas, que só fazem sentido em articulação com as duas anteriores, numa perspetiva holística, uma vez que "as competências não podem ser entendidas fora de um contexto" (Meyers et al., 2013, p. 361).

É preciso apostar claramente nas competências sociais, pois a produção social de significado é mais do que a soma das produções dos indivíduos. A escola deve integrar as RSO, desenvolver conhecimento no seio da inteligência coletiva, agir em comunidades com diferentes culturas e reconciliar dados em conflito. Não pode é continuar a preparar indivíduos para resolverem problemas individualmente, porque já não é isso que a sociedade pede aos cidadãos (Jenkins, 2009).

Também os encarregados de educação (EE) devem ter, desde cedo, um papel ativo com os seus educandos, reforçando as suas capacidades e competências emergentes. Em lugar de insistirem no controlo e proteção dos educandos, muitas vezes em relação a fenómenos que não conhecem bem, devem apostar na preparação dos educandos para a interação com os media, bem como na sua própria formação, uma vez que os media que os educandos usam hoje não fizeram parte da sua infância (idem, 2009).

Mas se o caminho está definido, há obstáculos a ultrapassar em termos de tecnologias da informação e comunicação (TIC) e media: i) existe um fosso de participação na faixa de crianças e jovens, pois não basta ter acesso mas é preciso saber usar de forma efetiva; ii) existe um problema de transparência, pois usar TIC e media para consumir e produzir mensagens não significa ser capaz de o fazer de forma crítica e reflexiva, o que obriga a uma preparação dos jovens nesse sentido; iii) existe uma questão ética, pois a escrita de crianças e jovens é mais pública que nunca, sem que estejam preparados para o fazer, pois usam novas formas de expressão que os adultos não dominam, estando assim pouco sujeitos a acompanhamento e supervisão.

\subsection{A ARTICULAÇÃO ENTRE A ESCOLA E OS CONTEXTOS FORA DA ESCOLA}

Urge perceber se é possível modernizar as instituições educativas, de modo a preparar os cidadãos para o século XXI (Redecker et al., 2010). Uma das tendências anunciadas para os próximos cinco anos é a mudança do papel dos professores em resultado da influência das TIC e do "impacto das plataformas de media sociais como o Facebook e o Twitter, que já estão a encontrar o seu caminho nas salas de aula" (Johnson et al., 2014, p. 1). Mas a escola ainda encara "0 uso dos novos media digitais como atividades de tecnologia da informação, e a literacia digital apenas como a aquisição progressiva de capacidades técnicas" (Underwood et al., 2013, p. 481).

Já os "espaços do mundo real, de contextos autênticos" (idem, p. 356) associados à aprendizagem informal, pouco privilegiados no discurso educativo, não podem continuar subaproveitados, pois potenciam a aquisição das competências próprias da idade da informação, desafiam os aprendentes à resolução de problemas em contexto social e implicam participação e engajamento. A aprendizagem informal deve ser encarada como "complementar e expansiva em relação ao que ocorre nas escolas e nos ambientes educacionais" (idem, p. 364), pois é uma for- 
ma de alargar a sala de aula às atividades quotidianas e de alargar as atividades diárias à sala de aula.

A preparação dos cidadãos é uma responsabilidade de todos os espaços de aprendizagem (incluindo a casa e o local de trabalho) e deve assegurar a preparação, a contínua atualização das capacidades ao nível da literacia digital, a compreensão e as práticas de todos os cidadãos, das crianças aos idosos (Meyers et al., 2013, p. 356).

Apesar do muito que se fez, é hoje clara a necessidade de serem desenvolvidos estudos na área da Digital Media and Learning (DMAL), não centrados no modo como as ferramentas digitais podem ajudar a atingir a aprendizagem, mas sim em como essas ferramentas, associadas a novas formas de convergência, de organização e de complexidade da cultura popular, "nos podem ensinar a atingir a aprendizagem, dentro e fora da escola, e como podem transformar a sociedade e o mundo" (Gee, 2010, p. 14).

As RSO são uma dessas ferramentas, pelo que importa perceber qual o seu papel na interação entre contextos de aprendizagem formal e informal. Compreender como crianças, jovens, professores e EE se relacionam com e através das RSO, que perceções têm do seu uso, o que fazem nas RSO, como comunicam e como aprendem (Ito, 2009) foram objetivos da investigação "As redes sociais e a nova literacia dos media" (2012-2015).

Este artigo está focado no uso de RSO por parte de jovens, seus professores e $E E$, e nas suas perceções em relação à aprendizagem com recurso a RSO. Procuramos perceber se há condições para uma "abordagem holística da aprendizagem", para continuar "a caminhar para um período onde os contextos formal e informal de aprendizagem interagem e trabalham em conjunto para criar ecologias de aprendizagem contínuas" (Meyers et al., 2013, p. 366).

\section{Metodologia}

Nesta investigação recorremos a uma metodologia mista, que prevê a recoIha de dados quantitativos e qualitativos, integrando-os, pois "a combinação das abordagens qualitativa e quantitativa permite uma compreensão mais completa do problema de investigação do que seria possível com apenas uma das abordagens" (Creswell \& Clark, 2013, p. 5).

Ao nível do design dos métodos mistos, Creswell (2014) considera três modeIos essenciais: o convergente paralelo (em que a recolha quantitativa e qualitativa de dados é concomitante), o exploratório sequencial (em que a recolha qualitativa acontece primeiro) e o explanatório sequencial (que consiste, primeiro, na recolha de dados quantitativos, na sua análise e na organização da fase qualitativa em função dos resultados: "os dados qualitativos iniciais são explicados depois com os dados qualitativos" (idem, p. 15).

A opção metodológica enquadrou-se na abordagem explanatória sequencial, aquela em que "os investigadores podem primeiro inquirir um grande número de indivíduos e depois fazer o seguimento com alguns participantes, de forma a obter os seus pontos de vista e opiniões acerca do assunto em causa" (idem, p. 20). Produzimos e validámos qualitativamente três questionários com professores, jovens, encarregados de educação e especialistas em Portugal, França e Itália. 
Os jovens (10-16 anos) responderam a um questionário de 32 perguntas, sendo uma com escala Likert e nove com escalas de intensidade. A amostra foi aleatória, tendo respondido os alunos previamente autorizados pelos EE (como exigido pelo Ministério da Educação e Ciência). 0 questionário teve como foco o uso e novos hábitos desenvolvidos pelos jovens nas RSO, para comunicação, aprendizagem com os pares e sua forma de relacionamento com outras esferas sociais, como a escola e a família.

0 questionário para professores tinha 25 questões, sete com escalas de intensidade, com foco os usos de RSO, percepção de usos por parte dos alunos, a relação das RSO com aprendizagens por parte dos alunos, percepção de riscos a que os alunos estão sujeitos e ações tomadas para fazer face a esses eventuais riscos. Responderam apenas professores que lecionavam aos alunos inquiridos.

0 questionário para EE tinha 22 questões, cinco com escalas de intensidade. Teve como foco os usos de RSO, percepção de usos por parte dos seus educandos, a relação com educandos e seus professores através das RSO, percepção de riscos a que os educandos estão sujeitos nas RSO e ações tomadas para fazer face a esses eventuais riscos. Responderam só EE dos alunos inquiridos.

Os questionários foram aplicados em 11 agrupamentos de escolas do distrito de Castelo Branco, a uma amostra de conveniência, entre janeiro e abril de 2013. Os jovens responderam em questionário impresso, na presença do investigador. Professores e EE responderam em papel ou online. Tratados os dados em SPSS, seguiu-se a realização de entrevistas de foco com 142 alunos e entrevistas semiestruturadas com 20 professores e $20 \mathrm{EE}$, que tinham sido inquiridos na fase quantitativa do estudo. As entrevistas decorreram entre janeiro e junho de 2014. Estes dados foram analisados com o programa Atlas.ti.

\subsection{Caracterização da amostra}

A amostra foi constituída por 549 alunos, 276 do sexo masculino (50,3\%) e 273 do sexo feminino (49,7\%), dos 10 aos 18 anos (apenas 0,6\% dos inquiridos tinham entre 16 e 18 anos), que frequentavam o $2^{\circ}$ Ciclo (41\%) e $03^{\circ}$ Ciclo do Ensino Básico ou o $10^{\circ}$ ano (59\%); $57 \%$ tinham até 12 anos.

Responderam $267 \mathrm{EE}$, sendo 78\% do sexo feminino. A maioria (85\%) tinha entre 36 e 50 anos. Um terço (33\%) concluiu o Ensino Secundário. Mais de um quarto (29\%) não concluiu o $12^{\circ}$ Ano e $10 \%$ concluiu o $1^{\circ}$ ou o $2^{\circ}$ Ciclo.

Participaram 150 docentes, 65\% do sexo feminino. A maioria (57\%) tinha entre 41 e 50 anos, sendo $72 \%$ licenciados, 16\% mestres, 6\% bacharéis, 5\% pós-graduados e $1 \%$ doutorados. No conjunto, lecionavam todas as disciplinas ministradas no $2^{\circ}$ e $3^{\circ}$ Ciclos.

$\mathrm{Na}$ fase qualitativa do projeto foram entrevistados 142 dos jovens inquiridos na fase quantitativa do estudo, sendo $52 \%$ do sexo masculino, $48 \%$ do sexo feminino (48\%); $60 \%$ tinham até 13 anos; $17 \%$ frequentavam o $2^{\circ}$ Ciclo e $83 \%$ frequentavam $03^{\circ}$ Ciclo e Secundário. Foram entrevistados 20 EE, com idades entre 30 e 51 anos, sendo 14 do sexo feminino. Dos 20 docentes entrevistados, com idades entre $42 \mathrm{e}$ 64 anos, 13 eram do sexo feminino. 


\section{Resultados}

0 estudo implicou a recolha de dados quantitativos e qualitativos que associamos na apresentação dos resultados encontrados.

\subsection{Acesso à Internet}

0 acesso à Internet através de computador pessoal (entre 60 e 63\%) é similar nos três grupos: jovens, EE e professores. É no computador da família que se verificam as maiores diferenças, pois é usado por metade dos alunos (52\%) e dos EE $(46 \%)$, mas apenas por cerca de um quarto (27\%) dos docentes (Gráfico 1).

Redes sociais: perceções de aprendizagem em ambiente formal, não-formal e informal por parte dos jovens (10-16), seus encarregados de educação e seus professores

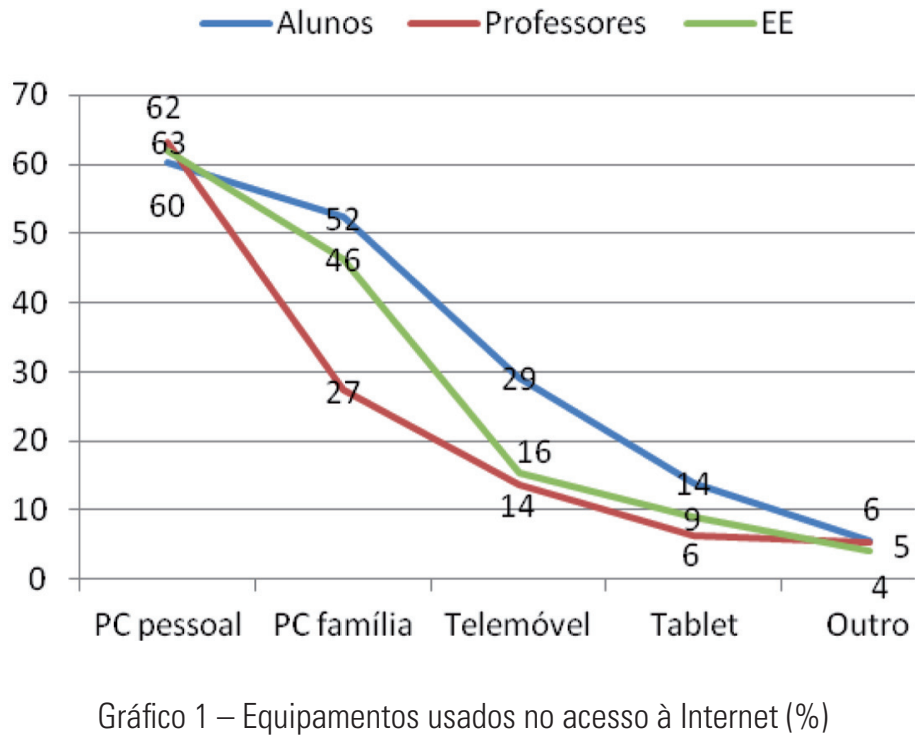

Os alunos utilizam mais os dispositivos móveis (29\% o telemóvel e 14\% o tablet), duplicando percentagens de professores (14\% e 6\%) e EE (16\% e 9\%). Não foi estabelecida diferença entre telemóvel e smartphone. Em Outros são referidos o computador da escola/biblioteca, o computador do emprego, computadores de acesso público, de amigos e familiares.

Entre os jovens há diferenças claras no acesso em função da idade e em termos de três dos dispositivos. Dos 10 para os 15 anos, o acesso via computador de família vai sendo abandonado: primeiro ultrapassado pelo computador pessoal, entre os 11 e os 12 anos e, depois, pelo acesso via telemóvel, aos 14 anos (Gráfico 2). 


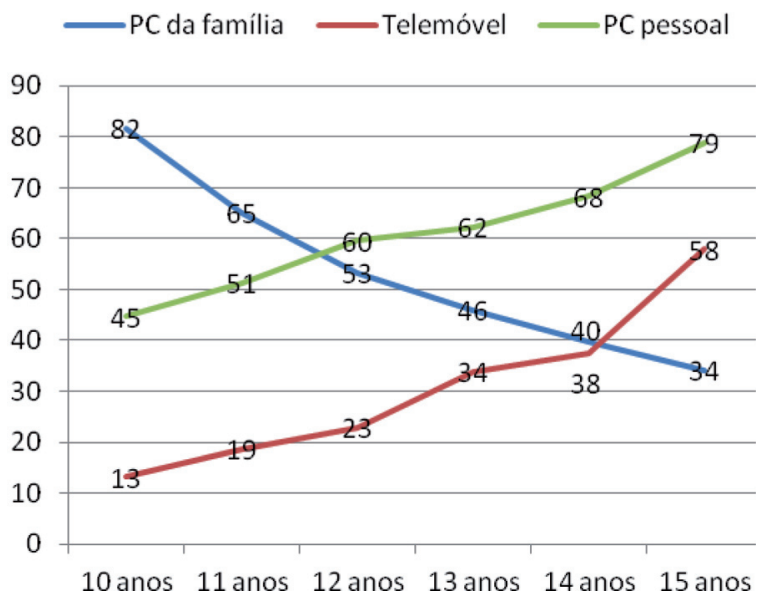

Gráfico 2 - Equipamentos usados pelos jovens no acesso à Internet, por idades (\%)

Continua a verificar-se a tendência dos jovens portugueses serem dos que mais acedem à Internet através de computador pessoal, quando comparados com os seus congéneres europeus, como mostrou o projeto EU Kids Online, segundo o qual 0 acesso por computador portátil pessoal por parte de jovens dos 9-16 anos (cerca de $65 \%$ ) mais do que duplicava a média europeia (cerca de 25\%) (Ponte, 2011). Valores idênticos foram encontrados pelo projeto Net Children Go Mobile, com 60\% dos jovens portugueses ( 9 -16 anos) a acederem diariamente à Internet através de computador portátil (média europeia de 46\%) e 35\% através de smartphone (média europeia de 41\%) (Mascheroni \& Olafsson, 2014, p. 9).

\subsection{USOS DE RSO}

Há mais jovens com pelo menos um perfil em RSO (91\%), que docentes (73\%) e EE (65\%). A rede mais utilizada é o Facebook (90\%), com percentagens próximas entre grupos (Gráfico 3).

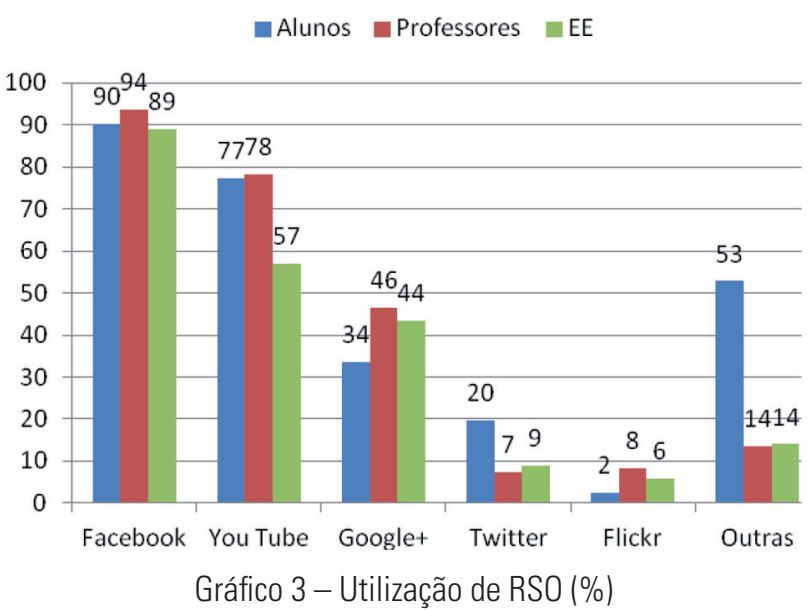


Seguem-se o YouTube, mais utilizado por professores e alunos que por $E E$, e 0 Google+, mais usada por adultos que adolescentes. Nas entrevistas foi discutida a possibilidade de os dados relativos a YouTube e Google estarem empolados, pois utilizadores do YouTube, mas que não têm perfil, referiram o uso. No caso do Google + terá havido confusão entre a RSO e o motor de busca Google. Professores e EE admitiram ambas as possibilidades. Os alunos admitiram apenas em relação ao Google+.

0 Twitter (20\%) é mais para jovens e o Flickr quase não é utilizado. Relativamente a "Outras", as percentagens são residuais entre professores e EE, mas interessantes entre alunos, que referem o Tumblr ( $12 \%$ do total) e 0 Ask.fm ( $8 \%$ do total).

Os alunos diversificam a sua presença online, usando diferentes RSO para fins diferentes, em simultâneo. No entanto, a média de redes usadas é similar, variando entre as 2,8 dos alunos, 2,5 dos professores e 2,3 dos EE. Os alunos tendem a usar um maior número de RSO que os professores e, estes, mais que os EE (Gráfico 4).

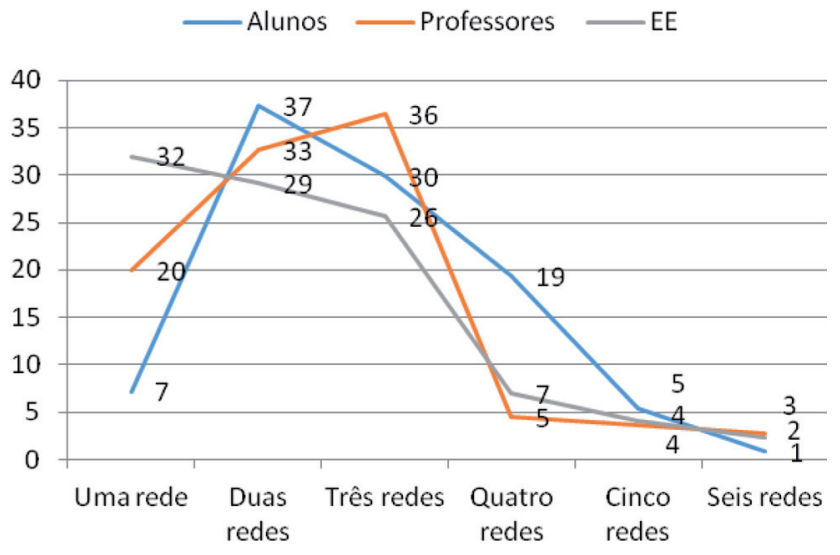

Gráfico 4 - Número de RSO utilizadas (\%)

São os adultos que mais usam apenas uma rede (32\% dos EE e 20\% dos docentes), sendo a percentagem residual entre alunos (7\%).

Os alunos são os que mais usam duas RSO (37\% contra 33\% dos docentes e $29 \%$ dos EE), mas os professores lideram no uso de três RSO (36\%, contra $30 \%$ dos adolescentes e $25,6 \%$ dos EE).

A diversificação chega às cinco RSO, mas sobretudo entre os alunos (respetivamente $19 \%$ e $5 \%$ ), sendo os valores residuais nas seis.

\section{Potencial pedagógico das RSO}

Sete em cada 10 professores reconhecem potencial pedagógico às RSO, mas as percentagens variam de acordo com o subgrupo em que colocámos os docentes (Gráfico 5). 0 potencial pedagógico das RSO é admitido por:

a. $78 \%$ dos docentes que usam RSO e por $48 \%$ dos que não as usam; 
b. $95,7 \%$ dos docentes que usaram as RSO com fins pedagógicos e por $60 \%$ dos que não usaram RSO com esse fim.

c. $88 \%$ dos docentes que falam com alunos acerca de RSO (e.g.: usos, conteúdos, estratégias de proteção...) e por 64\% que declaram não o fazer.

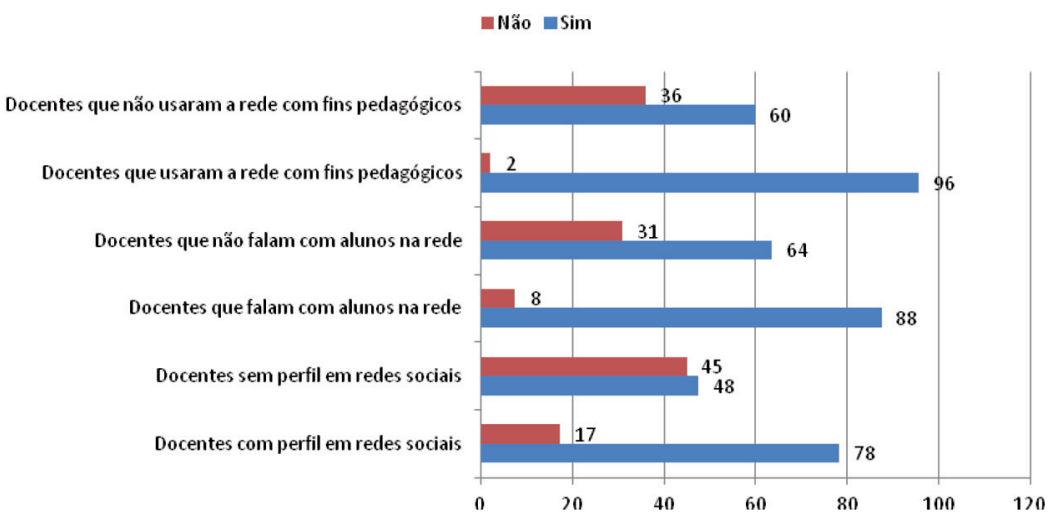

Gráfico 5 - Avaliação do potencial pedagógico das RSO por parte dos professores (\%)

Três em cada quatro docentes têm, pelo menos, um perfil numa rede social. Destes, $36 \%$ falam com alunos nas RSO e $43 \%$ já utilizaram a rede com fins pedagógicos. É, portanto, elevada a sua margem de progressão da utilização das RSO.

\subsection{Uso de RSO na escola}

Perguntámos a professores e jovens se concordavam que existe aprendizagem nas RSO relativa a conteúdos escolares. Mais de $80 \%$ dos alunos e dos professores consideraram que não (Gráfico 6).

Perspectiva do professor Perspectiva do aluno

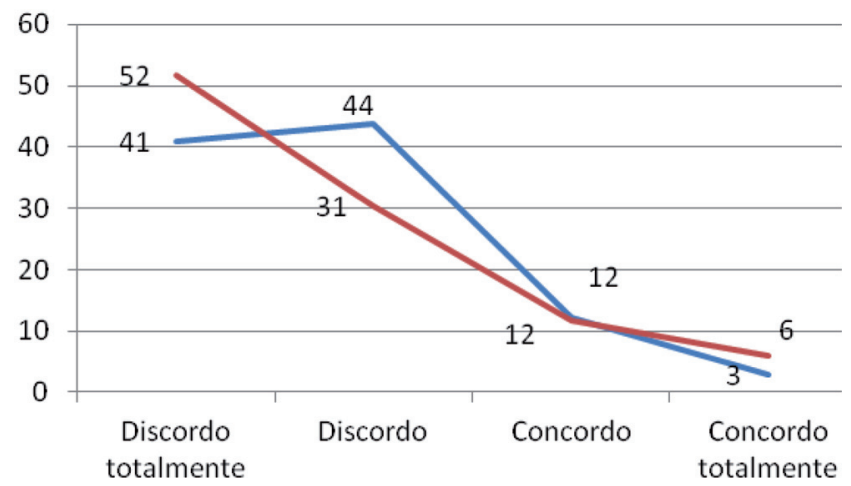

Gráfico 6 - Posição de professores e alunos em relação à aprendizagem de conteúdos escolares na rede (\%) 
Os alunos resistem a aprender conteúdos escolares nas RSO: "Se quisermos, aprendemos. Mas esse é que é o problema. Nós não queremos" (Rita, 16 anos). Mas alguns admitem aprender: "A professora de música publica no Facebook e também no site da escola. Aprendi lá coisas que me deram jeito nas aulas" (Gonçalo, 11 anos); "0 professor de Geografia costuma partilhar cultura geral e coisas assim" (Beatriz, 14 anos).

Os professores também se dividem. Um terço dos 20 entrevistados não admite o potencial pedagógico das RSO. "Não estou a ver que interesse pedagógico é que as redes possam ter" (P2), pois "é preferível usar as plataformas da escola, uma vez que é muito mais seguro e não há cá distrações, como é o caso dos jogos" (P22) e "se a rede fosse um espaço de estudo, pesquisa e investigação, deixavam automaticamente de ter interesse naquilo" (P14).

Os outros docentes acreditam no potencial pedagógico, já que "ainda só temos 10 anos de redes e o potencial vai ser cada vez maior" pois "qualquer dia os livros desaparecem e fica tudo no tablet" (P40). É preciso concretizar o potencial: "Eles veem as redes como espaço de entretenimento e de comunicação, sobretudo. Mas os professores têm a perspetiva que há aprendizagem" (P25).

Seis dos 20 docentes entrevistados usam ou já usaram RSO com fins pedagógicos. Uma professora de Música tem duas páginas Facebook nas quais partilha músicas, partituras e interage com alunos e EE. "Sei que, desta forma, não consigo chegar a todos. Mas se dois ou três aprenderem, já é bom. Tento usar todas as técnicas para chegar ao máximo número de alunos, para que eles aprendam" (P1).

Um professor de Geografia usa a página pessoal para interagir com os alunos, partilhando vídeos do YouTube. Num teste usou uma imagem que encontrou no Facebook sobre 0 sistema de transportes, que os alunos identificaram de imediato. "Era uma imagem de uma bicicleta para ilustrar os problemas dos transportes. Disseram que, se soubessem, tinham ido ao meu Facebook" (P24). Recorre ainda às RSO para planificar:

“Na aula de amanhã vou começar o Ambiente e Sociedade. Então, vou começar por Ihes passar o 'I'm sorry' do Michael Jackson. Estão a ver aqui, a desertificação, o macaco a passar para as florestas, estão a ver a água a faltar... Para passar a mensagem tens de ter uma âncora" (P24).

E usa as RSO para autoformação, interagindo com colegas, apresentando como exemplo um vídeo sobre a expansão dos oceanos:

"Na semana passada, alguém partilhou que, quando os oceanos gelam, também expandem. Automaticamente, partilhei. E copiei para mim, para mostrar nas aulas. Portanto, não vou ao Facebook procurar coisas, mas pode acontecer encontrar. Estou nos newsgroups de Geografia de Coimbra e estão sempre a partilhar no Facebook. E eu aproveito" (P24)

Uma professora de Português usou vídeos do YouTube. "Fui lá uma vez buscar coisas sobre Os Lusíadas ou sobre Fernando Pessoa. Achei interessante. Claro que tem de se visualizar previamente. Mas achei que estava correto. Não estava nada fora do científico" (P25). 
Um docente de Ciências da Natureza usa as RSO e outras TIC disponíveis, mas não o Facebook:

"Uso o YouTube para Ihes mostrar vídeos. 0 computador na sala está sempre ligado, porque tenho o manual digital e os miúdos não têm. Como todas as salas têm videoprojector, muitas vezes quero dar exemplos e uso o manual, as hiperligações para redes e, embora sem abrirem diretamente, reencaminham para o YouTube. Mas nunca usei o Facebook com esses fins" (P40).

Mas está seguro que os alunos o utilizam e aprendem conteúdos que são importantes nas aulas:

“Em plena aula, às vezes dizem: 'Alguém pôs uma coisa sobre isso no Facebook'. E quando falamos de notícias do dia-a-dia, também há muitas que aparecem no Facebook. Depois os alunos fazem perguntas sobre elas, por exemplo quando há uma descoberta científica importante ou quando houve um prémio de ciência" (P40).

Um docente de Educação Visual e Tecnológica considera que os alunos desenvolveram aprendizagens com RSO:

"Aqui há tempos publiquei uma coisa sobe a cidade cinzenta, em São Paulo, que tem a brigada cinzenta, que apanham graffiters e pintam tudo de cinzento. 0 cinzento tem um simbolismo extraordinário e fizeram um documentário sobre o tema. Sobre a guerrilha entre os grafiteiros e a brigada da tinta cinzenta. Foi muito interessante" (P10).

Um professor de Inglês usou uma página Facebook, onde coloca "todos os dias várias coisas, como tabelas de vocabulário ou de gramática, às vezes expressões idiomáticas". Partilhou com os alunos, mas as partilhas foram acolhidas de modo desigual:

"Eu colocava lá isso e algumas vezes eles comentavam: 'Oh stor, até aqui?'. Ou seja, acho que é uma coisa que ainda não está bem resolvida. Os miúdos ainda não consideram que as redes sejam uma plataforma de trabalho. Claramente que não. Acham que é entretenimento puro. Se nós Ihes conseguirmos ir dando umas injeções de algo que seja trabalho e vá ficando, isso tem de ser algo que os professores aprendam a fazer. (...) Eles aceitam, notícias da escola, calendarizações de atividades da escola, isso eles aceitam porque não acham que seja trabalho. Enquanto plataforma de divulgação de atividades da escola, sim. Enquanto plataforma de trabalho para as disciplinas, acho difícil" (P7).

Mais cautelosos são os docentes que acreditam no potencial pedagógico das RSO, mas que não as usaram nesse sentido: "Nós não temos noção daquilo que os alunos aprendem nas RSO. E como não temos noção, não as aproveitamos nesse sentido" (P10), assumindo que "o seu aproveitamento pedagógico tem de ser feito de uma forma quase sub-reptícia, uma vez que só uma minoria aceita aprender coisas das aulas no Facebook" (P7). E consideram que "é preciso haver uma outra preparação de professores e de alunos" (P8). 


\subsection{RS0 e aprendizagem não-formal/informal}

Perguntámos se concordavam que os jovens aprendem nas RSO acerca de assuntos que os interessam, mas não diretamente relacionados com a escola: 72\% dos professores considera que sim; 43\% dos jovens também (Gráfico 7).

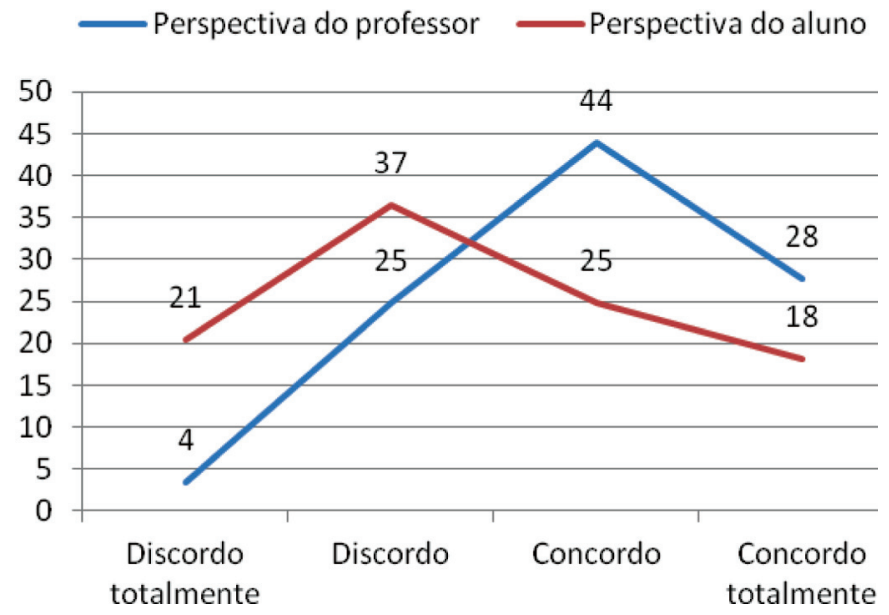

Gráfico 7 - Posição de professores e alunos em relação à aprendizagem de outros conteúdos na rede (\%)

0 nível de concordância dos alunos aumenta com a idade: de 10\% aos 10 anos para $35 \%$, aos 15 , o que poderá estar relacionado com a capacidade crescente de usarem as RSO e a Internet para encontrarem o que procuram, sendo que o leque de interesses se vai alargando com a idade.

Nas entrevistas, os alunos apontaram conteúdos que aprendem nas RSO e na Internet (que não distinguem por vezes), os quais organizámos em sete grupos:

a. Técnicas - aprendem a "construir objetos", "editar vídeo", "informática", ou a gerir a presença nas RSO: "aprendemos que não podemos estar sempre a publicar o que nos vem à cabeça e a comentar da maneira que nos apetece (António, 12 anos); "Aprendemos a usar melhor o Google para pesquisar páginas e a saber quais são as páginas Facebook onde estão as coisas que me interessam" (Mariana, 13 anos).

b. Jogos - "aprendo sobre jogos", "aprendi a jogar snookerna rede, sou um mestre" (João, 15 anos); "Eu jogo um jogo que se chama League of Legends e há páginas só sobre esse jogo. E mete lá muitas publicações. Eu vou lá ver e aprendo sobre o jogo, aprendo a jogar melhor (Miguel, 15 anos).

c. Notícias - as notícias são referidas frequentemente, sendo as que mais interessam as que se referem a mortes (morte de Eusébio, morte de Nelson 
Mandela), desporto e estrelas, sejam elas do espetáculo (e.g.: Justin Bieber) ou do desporto (e.g.: Cristiano Ronaldo).

d. Artes e espetáculo - aprendem mais sobre música, bandas, séries de televisão, filmes. "Eu ponho Gosto nas páginas e depois vou ver, por exemplo, bandas, filmes" (João, 13 anos).

e. Faits divers - os jovens referem frequentemente "anedotas", "truques de magia", "curiosidades".

f. Reflexões - "frases de pessoas importantes" a que não ficam indiferentes: "Vejo frases que são lições de vida e pendo nisso" (Madalena, 12 anos); "Isto pode ser bué estúpido, mas há certas lições de moral que me ajudam a compreender melhor as coisas. Há certas histórias sobre a vida que são boas, sem dúvida. Ainda somos muito novos e certas frases e coisas assim, ajudam a pensar um bocado" (Marta, 13 anos).

g. Inglês - frequentam a disciplina, mas o inglês que aprendem nas RSO e na rede é para outros fins. "Às vezes nem são palavras que usamos na escola, com os professores. São expressões que ouvimos dizer e que, depois, usamos entre nós" (Maria, 15 anos); "Eu aprendo inglês nas músicas e nas séries" (Inês, 13 anos).

Os alunos têm mais facilidade em falar de aprendizagens no ambiente informal das RSO, mas acabam por referir alguns exemplos de utilização da Internet e das RSO para aprenderem conteúdos escolares em contextos sociais informais, que potenciam as relações entre eles, como refere a literatura. "Eu, às vezes, antes do teste do Físico-Química, pronto, eu tenho um site, onde está tudo bem explicado. Já o partilhei ao Pedro e ao Luís" (Alexandra, 13 anos); "Tenho uma tia que é professora, que conhece muitos sites, sobre Inglês ou sobre Matemática. Se temos teste segunda-feira e estou a estudar no fim-de-semana e não percebo alguma coisa, vou procurar as respostas, esclarecer dúvidas" (Mariana, 11 anos): "Eu gosto de uma página Facebook que é só sobre música e onde vou tirar a maior parte das partituras que eu uso" (Leonor, 13 anos). Valorizam este tipo de aprendizagem em contexto informal, como refere a literatura e como se compreende do diálogo:

"- Quando estamos interessados num artigo e vamos lê-lo, aprendemos sempre alguma coisa. Porque na escola é sempre 'decora isto, decora aquilo..." (Marina, 13 anos)

- Sim, na escola nós estamos muito tempo para aprender só uma coisa. Estamos lá quanto tempo para aprender um verbo? Muito!" (Marcelo, 13 anos)

- Pois, e na Internet sempre vai variando. Aprendemos e não é uma seca tão grande" (Catarina, 13 anos).

\subsection{0 medo de EE e de docentes como limitador do potencial pedagógico das RSO}

Os EE aceitam que os jovens aprendem nas RSO, sobretudo acerca de outros assuntos que não os escolares. Mas estão mais preocupados com os perigos decorrentes da utilização das RSO do que com as suas potencialidades. 
$\mathrm{Na}$ fase quantitativa pedimos a professores e EE que avaliassem 10 ações comuns de jovens nas RSO, considerando-as de risco reduzido, médio ou elevado. 0 Gráfico 8 diz respeito apenas à opção 'risco elevado'. Os dados mostram que os professores atribuem mais perigo a essas ações do que os EE.

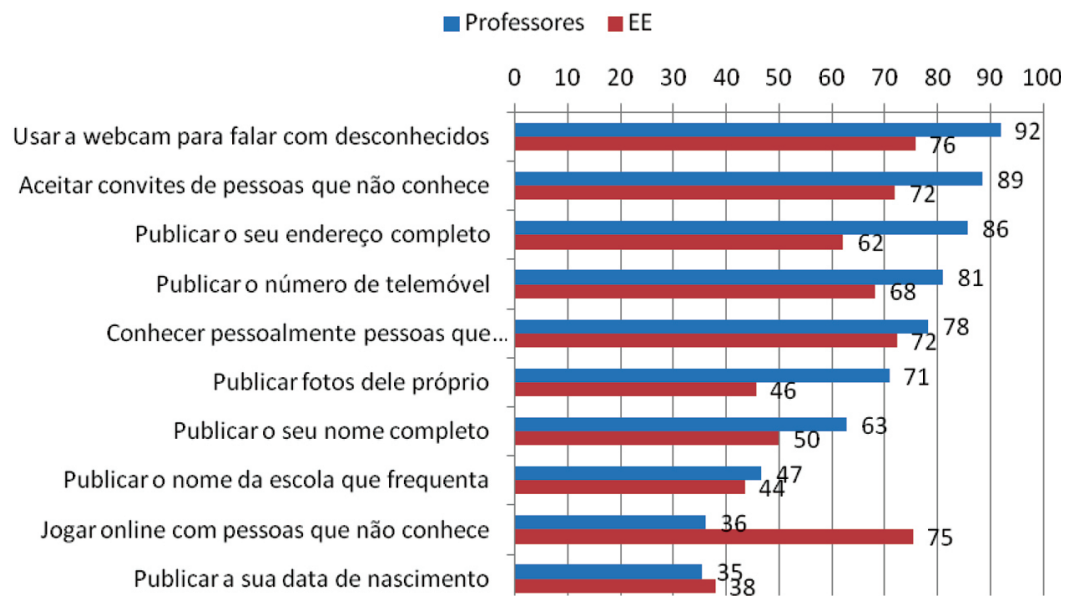

Gráfico 8 - Avaliação de risco das ações dos jovens na rede por parte de professores e EE (\%)

Utilizar a webcam para falar com desconhecidos é uma ação de risco elevado para $92 \%$ dos professores e $76 \%$ dos EE. Já "jogar online com pessoas que não conhece" é a segunda acção mais perigosa segundo os EE (75\%) mas uma das menos perigosas de acordo com os professores (36\%). Nesta ação e noutras como aceitar convites de pessoas que não conhece e publicar o nome completo, há mais 16 a $24 \%$ de professores que EE a considerá-las de risco elevado, o que é atribuído (nas entrevistas) a uma maior perceção do perigo ou por parte dos professores e/ou a um desconhecimento do perigo por parte dos EE.

Em média, $5 \%$ dos professores e 16\% dos pais consideram estas ações de risco reduzido; $91 \%$ dos docentes e $83 \%$ dos professores considera estas ações de risco médio ou elevado; $60 \%$ dos professores e EE consideram-nas de risco elevado. Já cerca de $5 \%$ dos professores e $3 \%$ dos pais referem afirmam não saber posicionar-se relativamente a estas ações. Organizámos cinco perfis a partir dos dados (Gráfico 9). 


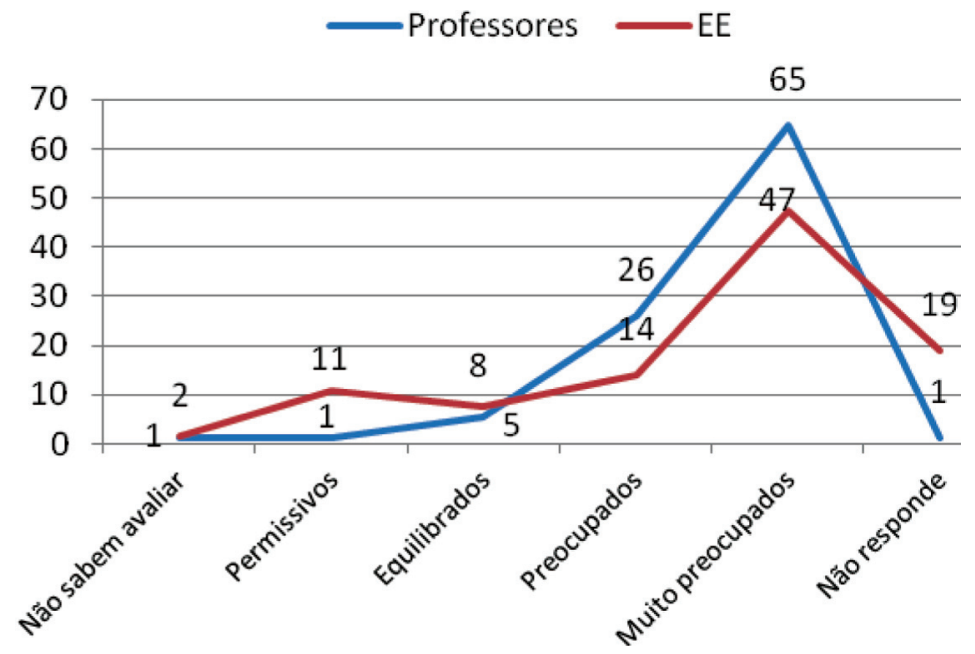

Gráfico 9 - Perfis de professores e de EE em relação à avaliação de risco

Cerca de $91 \%$ dos professores e de $61 \%$ dos EE estão preocupados ou muito preocupados em relação ao conjunto das ações referidas. A distribuição é menos desequilibrada entre EE. Porém, 19\% dos EE não responderam à questão, o que pode estar relacionado com a dificuldade em classificarem as ações quanto ao nível de risco.

Perguntámos a professores e EE se falavam com os alunos e com os filhos acerca da utilização de RSO. Os resultados mostraram que 35\% dos professores não 0 fazem, enquanto apenas $4 \%$ dos EE admitiram não 0 fazer.

Os docentes apresentam como razões para não o fazer o facto de nunca terem pensado nisso ("Nunca me ocorreu abordar esse assunto"; P13), a falta de tempo ("Tenho um programa extenso para dar. Não faz parte do programa, não é abordado, pronto"; P2). Outros falam como os alunos, mas não de forma organizada: "São conversas de circunstância, esporádicas" (P1); "Não o faço de uma forma premeditada" (P10).

São referidas ações para alunos que enquadramos na lógica da aprendizagem não-formal em ambiente escolar, como "uma ação de formação sobre segurança na Internet" (P13), o Dia da Internet Segura (P2), ou "a palestra da Escola Segura" (P40).

As conversas com os alunos acerca de RSO decorrem sobretudo na área disciplinar não curricular de Educação para a Cidadania (ministrada pelos diretores de turma), sendo encaradas pelos docentes como uma tarefa dos diretores de turma, que não tem continuidade: "quando era diretora de turma, fazia-0. Já não sou. Não o faço" (P22). Outro espaço é o da disciplina de TIC: "Uma das minhas batalhas é essa. É muito importante para eles, pois eles, muitas vezes, não têm a noção do perigo" (P23). Mas nem todos têm essa disciplina: "Nós só temos no 7. . e no 8. ${ }^{\circ}$ Foi uma estupidez terem acabado com TIC. Passámos a responsabilidade para os diretores de turma" (P7). Um professor de TIC conta a sua experiência:

"Há miúdos que criam perfis partilhados por causa dos jogos. Dão a password uns aos outros. Se um não consegue jogar naquela hora, vai jogar o outro. Não mu- 
dam a password e, quando se zangam, entram lá e tentam denegrir a imagem do outro. (...) É o que eu digo aos miúdos. Mas eles querem lá saber. Querem é utilizar e nem se preocupam. Desde que aquilo funcione, não há problema nenhum. A realidade é essa. (...) Muitos miúdos, quando criam a conta, e talvez nos aconteça também a nós, não adicionam aquelas informações de recuperação de password, como 0 email de recuperação ou o telemóvel. Mudam-lhes a password e perdem 0 controle da conta. Isso acontece" (P32)

Professores de outras áreas também falam com os alunos acerca das RSO e dos perigos. "Dei-Ihes o exemplo de um filme, o Trust'. Eles já o viram e disse-Ihes para verem o resultado. Digo-Ihes sempre que eles não sabem quem está do outro lado. Eles dizem tudo, a que horas saem, o que trazem vestido, de que turma são" (P23). Outras estratégias passam por casos particulares ou de questões dos próprios alunos:

"Há coisas que têm mesmo a ver com a matéria. Quando falo da globalização. Depois, às vezes, são eles que perguntam. Falo muitas vezes de casos que aconteceram, para os alertar do que lhes pode acontecer a eles" (P24)

As experiências dos alunos são âncoras usadas por professores para falarem com eles acerca de RSO. "Quando falo com eles, às vezes dão exemplos, ou de experiência própria ou de casos que ouvem. Às vezes concretizam. Aconteceu isto com um ou com outro" (P25).

A questão da segurança na Internet e nas RSO em particular "foi abordada no jornal escolar" e "é abordada pelos colegas sempre que pedem aos alunos pesquisarem algo na Internet" (P7).

Alguns docentes não se sentem preparados para abordar as RSO: "Muitas vezes não sei o que dizer porque não tenho muitos conhecimentos acerca de redes sociais" (P14). Se na fase quantitativa desta investigação, 35\% dos docentes afirmaram nunca ter falado com alunos acerca de RSO, um dos entrevistados considera pouco:

“Não deve ser só 35\%. Devem ser muitos mais. Há ainda um grande grupo de professores que tem um grande desconhecimento do que são as redes sociais, para que servem. Acho que esse grupo, desinformado, não vê mais nada nas redes a não ser os perigos" (P40).

Todos os EE que entrevistámos afirmam falar com os educandos acerca dos perigos a que estão expostos nas RSO, seja "ocasionalmente" (EE12) ou de forma mais organizada: "Temos uma atividade familiar uma vez por semana e é nessa altura que debatemos o que é novo, o que é necessário planear" (EE6). Há ainda quem admita "uma aprendizagem mútua nessas conversas" (EE1).

Os EE vão pelo exemplo: "estamos constantemente a ouvir coisas e eu faço questão de lhe contar" (EE4). E organizam "de vez em quando, uns seminários assustadores para Ihe contar aqueles casos horríveis que acontecem" (EE41). Mas tam-

1 Trust é um filme realizado por David Schwimmer, em 2010, que relata a história de uma jovem que, após ter recebido um computador como prenda da família, acaba por se envolver online com um homem adulto, que se faz passar por adolescente, e que acaba por ser violada. 
bém pelos conselhos: "Ajudo-0 a utilizar melhor, o que deve fazer, o que não deve fazer" (EE1). As regras mais referidas incidem no tempo de uso ("Tentamos limitar esse tempo, o que não é fácil porque o acesso é feito por telemóvel e não sabemos se está a jogar ou a comunicar" - EE41), não aceitar estranhos ("não pode ficar no quarto, fechado, mas sim na sala" - EE16), além de evitar revelar informação pessoal. Outra é a limitação do acesso, que sucede com os filhos mais novos: "Mesmo o meu outro filho, aos seis anos, ele fixa o que nós fazemos. Se the der liberdade, amanhã está na rede. Ele é capaz de fazer isso" (EE21).

Uma das estratégias dos EE passa pela interação com os educandos ("Partilhamos informação útil para ela no perfil dela. Ela gosta e às vezes devolve, envia informação que considera interessante - EE19). Outra baseia-se na confiança: "Precisamos de os conhecer bem, de Ihes dizer que confiamos neles. Mais do que proibir, é preciso dizer-Ihes 'Eu confio em ti'" (EE 27).

Após a análise das entrevistas ficou claro que há conversas sobre RSO entre EE e professores de um lado e os jovens do outro. Essas conversas decorrem no espaço formal e não-formal da escola e no espaço informal de casa. Mas são sobretudo centradas nos eventuais perigos a que os jovens estarão expostos ao usarem RSO. Os EE, por exemplo, limitam mesmo o tempo de uso, por não conseguirem mediar a utilização dos dispositivos, sobretudo os móveis, como o smartphone, que os jovens preferem utilizar, mesmo sendo em casa, precisamente pela privacidade que the confere, mesmo em relação à célula familiar restrita (Mascheroni \& Cuman, 2014). Esse medo de professores e EE pode resultar também de algum desconhecimento em relação à forma como funcionam as $\mathrm{RSO}$, o que leva a que muitos deles não se sintam preparados para discutir com os jovens, o que poderá contribuir para limitar o seu uso com fins pedagógicos.

\section{Conclusões}

Um conjunto de limitações, em ambas as fases da investigação, deve ser considerado aquando da interpretação e eventual generalização dos resultados encontrados: i) é um estudo não experimental, que não estabelece relações causais; ii) os questionários foram produzidos e validados pelo investigador, pelo que não tinham sido aplicados antes; iii) os dados foram recolhidos através de uma amostra de conveniência, no distrito de Castelo Branco e podem não ser generalizáveis a outros contextos; iv) os jovens que participaram nas entrevistas de foco, tal como os professores e EE que foram entrevistados individualmente, foram os que se disponibilizaram para o efeito, pelo que os resultados qualitativos poderiam ser diferentes se outros e não estes fossem os entrevistados.

Esta investigação revelou que as RSO têm potencial para concretizar a literacia digital e as competências a ela associadas, desde logo as competências técnicas, além de proporcionarem o acesso a múltiplas mensagens media, suscetíveis de análise crítica, e à produção crítica e criativa de mensagens. Abrem ainda as portas para múltiplas comunidades de aprendizagem que vão muito além dos contextos geográfico e cultural dos indivíduos.

Sete em cada 10 professores inquiridos reconhecem potencial pedagógico às RSO, sobretudo os que as usam com fins pedagógicos, os que têm perfis e que interagem com alunos através delas. Apesar disso e de existirem exemplos de boas 
práticas, apenas $15 \%$ dos docentes e $18 \%$ dos alunos concordam que há aprendizagem de conteúdos escolares nas RSO. Já a aprendizagem de conteúdos não escolares com recurso às RSO é admitida por $72 \%$ dos professores e por $43 \%$ dos alunos.

Professores e alunos separam claramente o papel das RSO no ambiente formal da escola e no ambiente informal da vida quotidiana e não encaram a aprendizagem numa perspetiva holística, segundo a qual formal e informal interagem e se complementam. Três ordens de razões justificam esta perceção: i) a falta de preparação dos professores, mas também dos alunos, que os docentes admitem; ii) docentes e alunos entendem as RSO como espaços de entretenimento e comunicação, pelo que os primeiros abdicam de 'perder tempo' a usá-los e os segundos apoiam a decisão; iii) as RSO são encaradas como espaços perigosos, pois $91 \%$ dos docentes e $61 \%$ dos EE estão preocupados ou muito preocupados com os riscos a que os jovens estão expostos, centrando a sua ação em alertar os alunos para os perigos e não para tirarem partido das RSO em termos de aprendizagem (Gee, 2010).

Concluindo, as RSO reúnem as condições para concretizar a interação entre os contextos de aprendizagem formal, não-formal e informal, rumo às "ecologias de aprendizagem contínuas" (Meyers et al., 2013), ao longo da vida. Mas urge desenvolver o nível de literacia digital de todos os cidadãos, com foco nos professores, alunos e $\mathrm{EE}$, o que implica mais investigação, formação no terreno, atividades no terreno e respetiva avaliação.

\section{Agradecimentos}

0 autor agradece à Fundação para a Ciência e a Tecnologia, que lhe concedeu a Bolsa de Pós-Doutoramento com referência SFRH/BPD/77874/2011.

\section{Referências}

Buckingham, D. (2009). Media Education Policy: The future of Media Literacy in the Digital Age: some challenges for policy and practice. In Euromeduc - Media Literacy in Europe. Brussels: Euromeduc.

Creswell, J. (2014). Research Design: Qualitative, quantitative and Mixed Methods Approaches. Thousand Oaks (CA): Sage.

Creswell, J. \& Clark, V. (2013). Designing and conducting Mixed Methods Research. Thousand Oaks (CA): Sage.

Endrizzi, L. (2012). Jeunesse 2.0: les pratiques rélationelles au Coeur des médias sociaux. Dossier d'actualité Veille et Analyse, 71, 1-24.

Gee, J. (2010). New Digital Media and Learning as an Emerging Area and "worked examples" as One Way Forward. New York: MIT Press.

Haddon, L. \& Livingstone, S. (2012). EU Kids Online: National perspectives, EU Kids Online, LSE, London.

Ito, M. (2009). Living and Learning with new media: summary of findings from the Digital Youth Project. New York: MIT Press.

Jenkins, H. (2009). Confronting the Challenges of Participatory Culture: Media Education for the 21st Century. New York: MIT Press. 
Johnson, L., Becker, S., Estrada, V., Freeman, A., Kampylis, P., Vuorikari, R. \& Punie, Y. (2014). Horizon Report Europe: 2014 Schools Edition. Luxembourg: Publications Office of the European Union, \& Austin, Texas: The New Media Consortium.

Lopes, P. (2015). "Muito entretenimento, pouca informação", European Journalism Observatory. Disponível em http://pt.ejo.ch/10108/literacia-dos-media/nativos-digitais-muito-entretenimento-pouca-informacao

Mascheroni, G. \& Cuman, A. (2014). Net Children Go Mobile: Final report, Deliverables D6.4 \& D5.2, Educatt, Milano, Itália.

Mascheroni, G. \& Ólafsson, K. (2014). Net Children Go Mobile: Cross-national comparisons. Report D3.3, Educatt, Milano, Itália.

Meyers, E., Erickson, I. \& Small, R. (2013). Digital literacy and informal learning environments: an introduction. Learning, Media and Technology, 38(4), 355-367.

Ólafsson, K., Livingstone, S. \& Haddon, L. (2014). Children's Use of Online Technologies in Europe, A review of the European evidence base, EU Kids Online, LSE, London.

Perulli, E. (2009). Recognising Non-Formal and Informal Learning: An Open Challenge. Quality of Higher Education, 6, 94-116.

Pew Research Center (2015). Teen, Social Media and technology overview 2015. Washington DC: Pew Research Center.

Ponte, C. (2011). Acessos e literacias digitais: resultados portugueses do inquérito europeu EU Kids Online, In S. Pereira (Ed.). Congresso Nacional Literacia, Media e Cidadania. Braga, Universidade do Minho: Centro de Estudos de Comunicação e Sociedade.

Redecker, C., Ala-Mukta, K. \& Punie, Y. (2010). Learning 2.0 - The impact of Social Media on Learning in Europe. Luxembourg: Office for the Official Publications of the European Communities.

Smith, L. \& Clayton, B. (2009). Recognising non-formal and informal learning: Participant insights and perspectives. Adelaide: Australian Government.

Statista (2015). "Leading social networks worldwide as of March 2015 ranked by number of active users (in millions)". Disponível em http://www.statista.com/statistics/272014/ global-social-networks-ranked-by-number-of-users/ By Statista - The Statistics Portal.

Underwood, C., Parker, L. \& Stone, L. (2013). Getting it together: relational habitus in the emergence of digital literacies. Learning, Media and Technology, 38(4), 478-494.

UNESCO (2011). Media and Information Literacy: curriculum for teachers. Paris: UNESCO. 